\title{
Funding defined benefit pension schemes: an integrated risk management approach
}

\section{Abstract of the London Discussion}

[Institute and Faculty of Actuaries, Sessional Research Event, London, 13 November 2017]

This abstract relates to the following paper: Cowling, C. A., Fisher, H. J., Powe, K. J., Sheth, J. P. and Wright, M. M. (2019) Funding defined benefit pension schemes: An integrated risk management approach. British Actuarial Journal, Cambridge University Press, 24. doi: 10.1017/ S135732171800034X.

The Chair (Ms M. B. Elliott, F.I.A.): Our discussion is on the paper "Funding defined benefit pension schemes: an integrated risk management approach".

Our topic is one that many of us who work in the pensions field, and our clients, will have been thinking about in some detail over the past year or two, if not longer. However, putting together a sensible framework for managing both funding investment and covenant risk is something that not all trustees and corporate sponsors have been able to do effectively. This paper suggests an interesting framework for thinking about that interaction.

Charles (Cowling), and his co-authors, are going to present the paper. We will then have comments from the opener before we open the meeting to questions from the floor.

Charles (Cowling) has 30 years' experience in pensions; first, at Mercer and now Jardine Lloyd Thompson. He served for three terms on the IFoA council and has also chaired the Pensions Board. He currently chairs the International Board and represents the Institute and Faculty of Actuaries (IFoA) on pensions at the Actuarial Association of Europe, as well as the International Actuarial Association.

In 2013-2014 he was Master of the Worshipful Company of Actuaries, and in 2015 he was Pensions Personality of the Year, thanks to some crazy marathon running.

Mr C. A. Cowling, F.I.A. (introducing the paper): One of the challenges with any approach to pension scheme funding is simultaneously trying to achieve two completely different aims. On the one hand, financing a long-term cash flow obligation and, on the other, providing security for an important part of peoples' personal savings.

This is illustrated by looking at the 5,800 remaining defined benefit (DB) pension schemes. Either they will pay their benefits in full or they will not and will end up in the Pension Protection Fund (PPF). The impact of this default risk is illustrated by some research carried out by the Pensions and Lifetime Savings Association (PLSA), which has shown the impact on members, even in schemes with a strong covenant, can be very significant. 
Funding would be very easy if we could ignore the possibility of default. Indeed, if there were no default risk, you might reasonably conclude that a pay-as-you-go approach was the simplest and most efficient approach for funding.

In addition, there is the important and welcome challenge from The Pensions Regulator (TPR) that pensions funding has to be looked at in the context of a holistic, integrated risk management framework.

Our paper looks at funding within the current regulatory environment in the United Kingdom and does not attempt to comment on the optimal framework we might suggest were we able to start with a blank sheet of paper.

I will now hand over to my co-authors.

Hannah (Fisher) will talk about some of the relevant background research that we carried out to set the context for this paper.

Jignesh (Sheth) will then look at some of the investment perspectives which we believe are important.

Then Murray (Wright) will outline the funding framework that we are proposing.

Mrs H. J. Fisher, F.I.A. (introducing the paper): The first part of our paper is about setting the scene and providing some important context for our proposed funding methodology.

Many of you here will be very familiar with a lot of this background. We just wanted to touch on a few key findings from our research.

The Pensions Act 1995 arose, in the main, in response to the public concern following the Maxwell scandal of the early 1990s, and the subsequent Goode Committee report which recommended a minimum solvency requirement to secure the pension rights of members.

Up until 1997, there had been minimal UK legislation requirements about the level of assets an ongoing scheme needed to hold. The funding objective of the Minimum Funding Requirement (MFR) was for a scheme to hold enough assets to meet its liabilities. First, to provide all active or deferred members with a cash equivalent transfer value and, second, to secure annuities for all pensioners.

The MFR was the first real UK regulatory attempt to answer the dual challenge that Charles (Cowling) referred to earlier of how to finance the long-term cash flow obligation and to provide acceptable security for members' benefits.

An important feature of the MFR was that where a deficit was identified, it required full funding to be reached in a prescribed and relatively short time horizon. For the majority of schemes below $90 \%$ funded, there was a requirement to reach $90 \%$ funding within 1 year, with all schemes targeted to reach full funding within a 5 -year recovery period. This was a very different environment to the one that we see today, where 1-year or even 5-year recovery plans are not the norm. 
One of the questions that we were keen to ask in the paper was whether the current more flexible scheme-specific funding regime results in better or worse outcomes than a formulaic approach like the MFR.

Without a crystal ball it is quite difficult to consider how the MFR would have evolved over time. However, our simple analysis of the core principles behind MFR suggested that MFR would likely have produced a higher funding target now for the majority, although we accept not all, of schemes under the current scheme-specific funding regime.

We also believe that continuation of MFR would likely have resulted in many pension schemes moving towards a matched investment position more quickly than has happened in reality.

Does this, therefore, suggest that the old formulaic approach of MFR is better than the schemespecific funding model that we have today? And are we, as actuaries, really adding value and creating better outcomes for our clients?

We have considered some of the evidence. Given scheme-specific funding regimes and TPR's emphasis on employer covenants and integrated risk management, particularly over recent years, it might be reasonable to expect that we should be able to see a strong link between covenants, investment and funding across UK pension schemes.

The data that follows has been drawn from the latest available statistics published by TPR. We appreciate that TPR's analysis is based on group data and is not without its limitations and so we are simply presenting the published evidence from across the UK pensions landscape.

We do acknowledge that many scheme actuaries and pension schemes will be adopting a schemespecific approach, which does take into account, among other things, both the employer's covenant and a scheme's investment strategy.

Looking first at discount rates and covenants in the slide that you can see in Figure 1, we might expect pension schemes with a stronger employer covenant, that is, those in category CG1, defined by TPR, to adopt a higher discount rate than those schemes with a weaker employer covenant.

Nominal discount rate by covenant

\begin{tabular}{|c|c|c|c|c|}
\hline Covenant & $\begin{array}{c}\text { Valuation } \\
\text { tranche } 7 \\
\text { Sep } 11-\text { Sep } 12\end{array}$ & $\begin{array}{c}\text { Valuation } \\
\text { tranche } 8 \\
\text { Sep } 12-\text { Sep } 13\end{array}$ & $\begin{array}{c}\text { Valuation } \\
\text { tranche } 9 \\
\text { Sep } 13-\text { Sep } 14\end{array}$ & $\begin{array}{c}\text { Valuation } \\
\text { tranche } 10 \\
\text { Sep } 14-\operatorname{Sep} 15\end{array}$ \\
\hline Strong (CG1) & $4.34 \%$ & $4.13 \%$ & $4.64 \%$ & $3.46 \%$ \\
\hline $\begin{array}{l}\text { Tending to } \\
\text { Strong (CG2) }\end{array}$ & $4.32 \%$ & $4.18 \%$ & $4.51 \%$ & $3.50 \%$ \\
\hline $\begin{array}{l}\text { Tending to } \\
\text { weak (CG3) }\end{array}$ & $4.29 \%$ & $4.11 \%$ & $4.49 \%$ & $3.50 \%$ \\
\hline Weak (CG4) & $4.16 \%$ & $3.95 \%$ & $4.32 \%$ & $3.43 \%$ \\
\hline
\end{tabular}

Figure 1. Nominal discount rates by covenant 
Evidence from tranche 7 valuations, as indicated by the first column in the table, does tend to agree with this. Those schemes with the stronger covenant did tend, on average, to use a higher discount rate. However, the difference between the average discount rates used is only just under $0.2 \%$ per annum.

Earlier, Charles (Cowling) referenced research carried out by the PLSA which shows that the default risk varies significantly between strong and weak covenants, and so we might naturally expect a wide range of discount rates rather than the $0.2 \%$ shown.

In the valuations occurring 3 years later, that is those in tranche 10, in the last column, the gap narrows to $<0.1 \%$ per annum. This suggests that perhaps the strength of the employer covenant is not really influencing the choice of discount rate as much as we might expect for a scheme-specific funding approach.

Some may argue that the use of the TPR's valuation tranches is not a fair analysis. In Figure 2 we track the cohort of pension schemes through four triennial valuation cycles. We start with the tranche 1 valuation and go through to the tranche 10 valuation 9 years later.

As is touched on in our paper, the regulator's approach has naturally evolved over the past 10 years as it has reacted to changes in market conditions and changes in the behaviour of both trustees and employers. Naturally, we may have expected trustees' assumptions and, in particular, the discount rates, to become more scheme-specific over time.

This data show that while there was an increase in the interquartile range of just under $0.2 \%$ per annum, from 0.56 to 0.73 between tranche 1 and tranche 4 , since then there has been very little change in the range of discount rates adopted by pension schemes relative to gilts.

Figure 3 focusses on the data released by TPR in relation to tranche 10 valuations. The ratio of the technical provisions (TPs) to the buyout liabilities should give an indication of the prudence incorporated into the TPs and so we might expect to see a link between this ratio and covenant strength.

However, as you can see from the figure, analysis of the tranche 10 valuation does not provide us with any strong evidence of this.

Similarly, notwithstanding other factors, the weaker the employer covenant, the lower the proportion of return seeking assets we might expect the pension scheme to hold. Again, looking at the

Nominal discount rate distribution

\begin{tabular}{|c|c|c|c|c|}
\hline & $\begin{array}{c}\text { Valuation } \\
\text { tranche } 1 \\
\text { Sep } 05-\text { Sep } 06\end{array}$ & $\begin{array}{c}\text { Valuation } \\
\text { tranche } 4 \\
\text { Sep 08-Sep } 09\end{array}$ & $\begin{array}{c}\text { Valuation } \\
\text { tranche } 7 \\
\text { Sep } 11-\text { Sep } 12\end{array}$ & $\begin{array}{c}\text { Valuation } \\
\text { tranche } 10 \\
\text { Sep } 14-\text { Sep } 15\end{array}$ \\
\hline Upper quartile & $5.55 \%$ & $5.73 \%$ & $4.66 \%$ & $3.84 \%$ \\
\hline Median & $5.23 \%$ & $5.38 \%$ & $4.31 \%$ & $3.47 \%$ \\
\hline Lower quartile & $4.99 \%$ & $5.00 \%$ & $3.94 \%$ & $3.10 \%$ \\
\hline $\begin{array}{l}\text { Inter-quartile } \\
\text { range }\end{array}$ & $0.56 \%$ & $0.73 \%$ & $0.72 \%$ & $0.74 \%$ \\
\hline
\end{tabular}

Figure 2. Nominal discount rate distribution 
Ratio of TPs to buyout liabilities

\begin{tabular}{|l|l|}
\hline \multicolumn{1}{|c|}{ Covenant } & \multicolumn{1}{|c|}{$\begin{array}{c}\text { Valuation } \\
\text { tranche 10 } \\
\text { Sep 14 -Sep 15 }\end{array}$} \\
\hline Strong (CG1) & $67.6 \%$ \\
\hline $\begin{array}{l}\text { Tending to } \\
\text { Strong (CG2) }\end{array}$ & $70.1 \%$ \\
\hline $\begin{array}{l}\text { Tending to } \\
\text { weak (CG3) }\end{array}$ & $68.0 \%$ \\
\hline Weak (CG4) & $74.7 \%$ \\
\hline
\end{tabular}

Distribution of return seeking assets

\begin{tabular}{|l|l|}
\hline \multicolumn{1}{|c|}{ Covenant } & \multicolumn{1}{c|}{$\begin{array}{c}\text { Valuation } \\
\text { tranche 10 } \\
\text { Sep 14 -Sep 15 }\end{array}$} \\
\hline Strong (CG1) & $59 \%$ \\
\hline $\begin{array}{l}\text { Tending to } \\
\text { Strong (CG2) }\end{array}$ & $57 \%$ \\
\hline $\begin{array}{l}\text { Tending to } \\
\text { weak (CG3) }\end{array}$ & $58 \%$ \\
\hline Weak (CG4) & $55 \%$ \\
\hline
\end{tabular}

Figure 3. Tranche 10 valuations

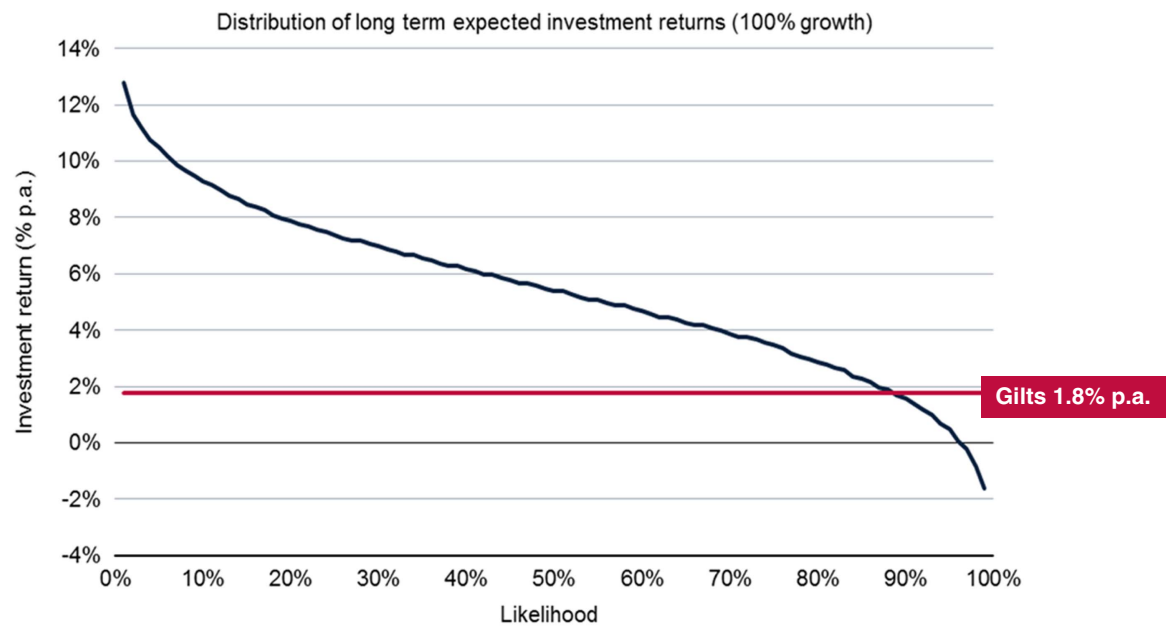

Figure 4. Potential distribution of investment returns

regulator's data from tranche 10 valuations, there is not much evidence of a link between the distribution of return seeking assets and covenant strength.

We acknowledge that many schemes are adopting a scheme-specific approach, but the evidence referenced here suggests that is not case for all UK pension schemes.

Within the paper we have also looked at how different regulatory frameworks have evolved across the globe to meet some of the challenges that we face here in the United Kingdom.

We do not have time to look at these in more detail, but what is notable is that the United Kingdom is not alone in our struggle to attain a robust pension funding framework in the current financial environment and strike the right balance between affordability, adequacy and security.

One of the challenges that all countries face is how to communicate this balance, and the risks attached to the delivery of pension benefits, to members.

My colleague, Jignesh (Sheth), is going to talk through some of the investment strategy challenges considered in our paper. 
Mr J. Sheth (introducing the paper): It is important to stress that this is not a modelling paper. However, as Murray (Wright) will explain, the framework in our paper relies on building and understanding the range of possible outcomes from the pension scheme's investment strategy and quantifying their likelihood.

The chart in Figure 4 shows a potential distribution of investment returns for a particular portfolio. For example, we would expect a return of at least $9 \%$ per annum with a $10 \%$ level of confidence, and a return of at least $5.4 \%$ per annum with $50 \%$ confidence.

There are a number of ways of deriving a distribution, but no method is perfect. One could use historic returns, but there is no guarantee that these would be repeated, and the amount of information, particularly for longer-term discrete periods, for example, over 20 years, is limited.

It is possible to use stochastic models but those based on normal distributions can understate the frequency and the magnitude of adverse outcomes. More sophisticated asset models attempt to address this but there is always an element of subjectivity with the output only as good as the inputs. Applying deterministic stresses on assumed scenarios could be as useful.

There are a number of other factors to consider in deriving the distribution. First, what is the correct time period? Over the longer term, the risk is not achieving the level of investment returns assumed relative to the liabilities, in which case the gap needs to be filled in some other way. Over the shorter term, can the sponsor afford the impact of distressed markets and the potential increase in deficit and therefore contributions?

Second, we need to consider what we are measuring against; the chart shows absolute returns but it may be more relevant to consider returns relative to gilts or inflation. A key feature of our framework is that it is not dependent on a gilts-plus approach, it could be applied to any model of future investment returns.

Another important factor is the effect of cash flows, which could be of particular concern for more mature schemes, and need to think about how the investment strategy should change to meet disinvestment in the future. Our framework encourages the investment modelling to consider not only the existing strategy, as set out in the statement of investment principles, but also how it is expected to change in the future.

Many pension schemes hedge key risks and expect a static investment strategy. Others, however, anticipate future de-risking. Such anticipated changes should be outlined in the statement of funding principles and reflected in any modelling.

Determining the appropriate measure for the scheme's TPs will involve the trustee's and sponsor's long-term objectives, the strength of sponsor covenants, risk tolerances, the intended investment strategy and how this is to develop. These factors are inextricably linked and will require an iterative process for setting assumptions in the funding strategy.

It is not the intention of this paper to say whether gilts-plus is the correct approach or whether something else is appropriate, such as an absolute return or inflation-plus. However, within the current regulatory regime, there must be an awareness of the cost of buying out a scheme's liabilities 
and recognition that the employer covenant supports the difference between the value of the pension scheme assets and the buyout cost of the liabilities.

The strength of the employer covenant clearly influences what is an acceptable margin between the TPs and the buyout cost, although just because a gap can be supported does not mean that it is the desired position.

Turning to the right-hand side of Figure 5, for many schemes the circumstances are such that the deficit cannot be quickly reduced to a position more in line with the size and strength of the company covenant. That should not mean compromising on the TPs. It is possible to reduce risk in the investment strategy, reflecting what can be supported by the employer covenant. However, risk management in achieving a clear understanding of the level of risk being run may well be more important than risk minimisation, as few pension schemes have the luxury of funding their obligations without taking some investment risk.

Murray (Wright) will now outline our proposals for a transparent and objective framework for funding pension schemes.

Mr M. Wright, F.F.A. (introducing the paper): Two of the key challenges we set ourselves when developing the framework for the sessional paper were how do we establish a framework that has an obvious link to the strength of the employer covenant? And how do we ensure that there is transparency, understanding and agreement on the amount of risk being run within the pension scheme?

We felt that if the funding framework could address these two challenges, then it would represent a possible step forward.

The first step in the process is for all stakeholders to agree a funding objective for the pension scheme. Many pension schemes already do this although not all. The objective might simply be to meet benefits as they fall due, so continuing to pay pensions until the last member dies. In this case you are going to be relying on the employer covenant over an extended period of time.

At the other end of the spectrum, you might be targeting full settlement of liabilities, so passing those liabilities on to an insurer. We have an intermediate objective where we are targeting a level of

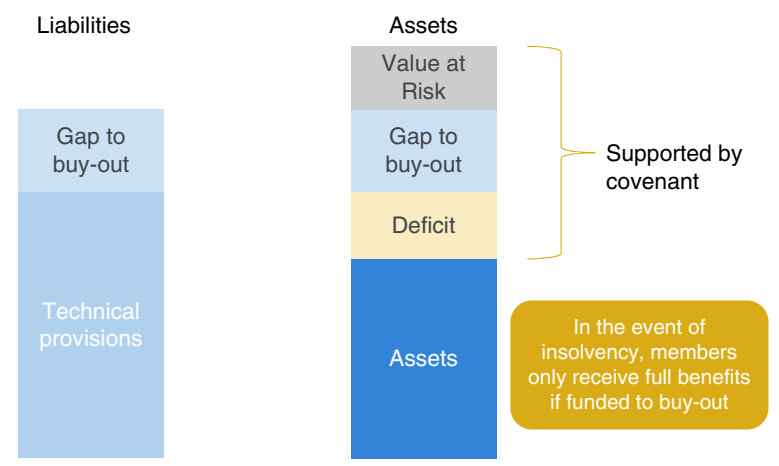

Figure 5. Covenant support 
funding that will give us confidence that we can meet members' benefits in full with a high degree of certainty and minimal reliance on the employer covenant on an ongoing basis.

We then examine the employer covenant. There is much helpful guidance from TPR and others regarding this. There is independent covenant assessment these days. The key to this step is to be able to place a relative score on the employer covenant. Different structures, say 1-5 or 1-10 or something completely different, do not matter. They can still be adapted within the framework.

We then make a direct link between the different covenant groups and a level of confidence that we wish to achieve. There is some background in the paper on why we have chosen these particular levels of confidence. Again, as long as you have a specified structure, the exact levels are up to you.

We suggest you work with $60 \%$ confidence for a strong covenant up to $90 \%$ confidence for a weak covenant, simply reflecting the fact that you are going to need more certainty in a funding plan if the support from the sponsoring employer is not as strong.

Then I bring you back to the chart that Jignesh (Sheth) showed you earlier. I have added some lines onto this in Figure 6. The red dotted line that you can see on the screen simply represents the long term, best estimate, expected investment return from this particular strategy and using this particular model. That is $5.4 \%$ per annum.

Everything to the right of that red dotted line can be thought of as a prudent expected return. We are considering this for our different confidence levels.

For a strong covenant, we would be targeting $60 \%$ confidence. Under this model, we would expect returns of at least $4.7 \%$ per annum. Thus we would use a discount rate of $4.7 \%$ per annum.

For a tending to weak covenant, where we are targeting $80 \%$ confidence, we would expect returns of at least $2.9 \%$ per annum, so we would use a discount rate of $2.9 \%$ per annum.

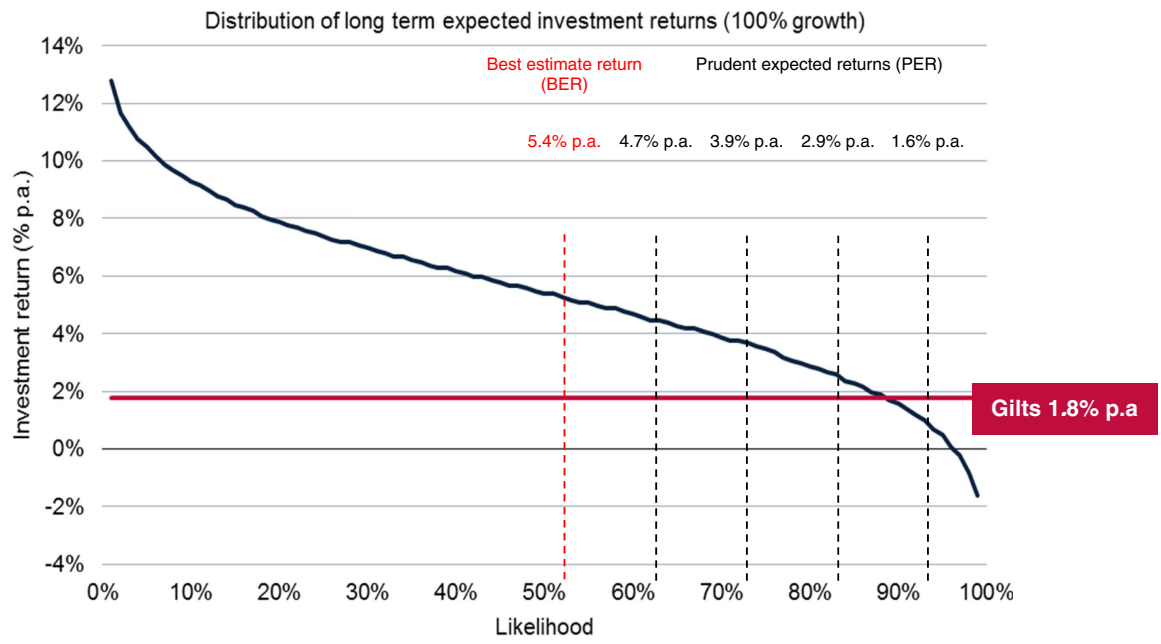

Figure 6. Set discount rates 
For simplicity, we are showing single discount rates here. It can also be applied in different ways, allowing for de-risking or basing it around a yield curve.

With this approach you end up with a wider variety of potential discount rates, in particular compared to the regulator's research that Hannah (Fisher) described earlier. Importantly, the discount rate you arrive at is directly influenced by the long-term investment strategy and the employer covenant in a very structured and transparent way.

This also means you are more likely to have a wider variety of potential deficits based on this approach. For genuinely strong covenants, we might even see a weakening of the funding target. For a weak maybe tending to be weak covenant, you might see higher liabilities and higher deficits.

Despite the increased variance in deficits there are still recovery plans to deal with, and ensuing discussions with the employer and the trustees.

One of the recommendations of the paper is to adopt best estimate investment returns within the recovery plan as standard. The reasoning behind this is if you have gone to the trouble of deriving a robust funding target, that fully reflects the funding strategy, then there is no need to layer more prudence into the recovery plan itself. We suggest that using best estimate returns produces a more transparent output. The end date for the recovery plan that you are targeting is when you actually expect to reach the target. It also makes it easier to monitor progress against that recovery plan over time.

This approach will provide some easing of recovery plans for certain schemes. So, alongside that we recommend a more disciplined approach, where you make a direct link between affordability levels and the length of the recovery plan.

Some possible limiting time periods were suggested in the paper: 5 years for strong affordability ranging up to 15 years for weak affordability. These are suggestions to promote debate and discussion. They are not prescribed as part of the framework. If, for example, you do have a strong overall covenant, and strong affordability, under the framework you might be targeting a lower deficit, so it is a reasonable expectation that you might be able to meet that deficit over a shorter period of time.

For weaker affordability levels, you do know that you are going to make reference to that level of affordability and you are going to need more time to reach full funding.

It is also worth noting that overall covenant strength does not always align with affordability. You can have examples where you have cash-rich employers with weak balance sheets and vice versa.

The final step of the process is to review the funding approach agreed as a whole for robustness. Can the employer manage the level of risk implied? This might involve stress and scenario testing over the inter-valuation period or to the end of the recovery plan. We can refer back to the analysis of Jignesh (Sheth) of the likelihood of achieving different levels of investment returns over different time periods.

It is also very important for the trustees to explore the likely scenarios where the deficit might become unsupportable by the employer covenant. 
The trustees should also check whether the employer covenant can support the level of implied selfinvestment risk that is represented by the pension scheme. That is the difference between the buyout liabilities and the targeted funding liabilities or the TPs as discussed earlier.

The paper suggests a maximum level of implied self-investment of $50 \%$ of the value of the employer balance sheet. That $50 \%$ level has been chosen to allow for a potential deterioration in the balance sheet over time and also for the fact that on insolvency the value of the balance sheet may be lower.

The $50 \%$ level is debatable, but the aim is the imposition of some sort of limit to instil discipline into the process.

If it does become clear that the funding strategy determined in the model is not achievable in practice, you may need to take a step back in the process to review your assessment of the employer covenant or the long-term investment strategy.

It may take a number of iterations in the process to reach a solution which is acceptable for all parties. In the end, the process itself should help to meet many of the requirements of integrated risk management.

Our challenge was to establish a funding framework with an obvious link to the strength of the employer covenant and our process set out in the paper meets that challenge. We also wanted to ensure that there is transparency, understanding and agreement on the level of risk being run within the pension scheme and the process helps to achieve that.

The proposed framework also allows actuaries and trustees to enhance their monitoring of the progress of the funding of the pension scheme over time. If there are changes in covenant level or investment strategy, for example, in between triennial actuarial valuations, you can allow for that in a very structured way.

A final recommendation of the paper was that based on the valuation process alongside statutory documentation, like the statement of funding principles, a short and succinct integrated risk management statement is produced which covers the key topics I have covered. These include: the objective of the pension scheme; the long-term investment strategy; a summary of the covenant analysis as well as the robustness checks carried out and the recovery plan agreed. The idea of this being that this statement could be picked up by a third party who could quickly understand exactly what the pension scheme is trying to achieve and how it is going to go about achieving it.

The Chair: I will now ask Stephen Rees to open the discussion. Stephen (Rees) has 24 years' experience as an actuary and adviser on a full range of pension scheme issues. He has worked with a mixture of United Kingdom and global companies in a variety of corporate sectors. He has held a scheme actuary practising certificate since introduced in 1997. After 30 years at Towers Watson, he joined Capita in 2014, where he is now the chief actuary.

As well as advising his own clients, he has responsibilities for professional standards, integrated risk management and assumption setting. He is also a member of the IFoA's Pensions Board. 
Mr S. P. Rees, F.I.A. (opening the discussion): I am not speaking on behalf of the Pensions Board or my employer. I welcome this paper. Giving good advice on the funding of -DB pension schemes, and on the understanding of their ultimate cost and the associated risks, is why pensions actuaries are employed. We have a seat at the table of decision-makers more readily than any other adviser. We need papers like this to test ideas, make us aware of different opinions and enable us all to give the best client-specific advice.

The paper itself covers a large number of areas, not all connected. I plan to make some initial observations about a number of these in the hope that this will encourage debate.

The authors point out the lack of evidence that employer covenant strength is making any difference to investment and funding strategy. We also know that the regulator equally frustrated by this. The statistics are, to some extent, affected at one end by strong employers choosing cautious strategies, and at the other end by trustees with weak employers choosing pragmatic strategies, because they seem to be the only way to make the numbers add up. We can usefully discuss whether the problem is the design of the legislation, or specific to implementation or even whether there is a problem in the first place.

The first reference to there being two objectives in pension funding is in the Introduction. The first objective is answering the question "what do we think is going to happen?" with an ongoing method, and the second is answering the question "what happens if the employer fails?" and we use a solvency method. The worst thing that we can do is attempt to fudge the two separate questions into a single one. This is one of the lessons we learnt from the MFR, which takes us to Chapter 2.

I was slightly disappointed that the history lesson began only 15 years ago. Actuaries under the age of 45 did not live through the decades when pension funding made sense. Until about 1990, the ongoing funding target was almost always higher than the discontinuance target.

For those who did not live through the process of the MFR being proposed, designed, debated and implemented during the mid-1990s, I will mention that one of the most important achievements of the actuarial profession was nothing to do with the mathematics of the MFR. The first version was called the Minimum Solvency Requirement and, to our credit, our profession explained to the politicians the difference between solvency and funding.

On one point of detail, I do disagree with paragraph 2.3.12. Most actuaries know that when using a dual discount rate, they know that they are creating a model that reflects an evolution in the scheme's future investment strategy.

Then we have Chapter 4, which does not have a clear connection with the previous chapters or the subsequent chapters. The subject described as "financial economics" does, however, have the ability to generate a lot of arguments amongst actuaries. I am disappointed that the many papers referred to in this chapter do not include the paper presented in this hall to the Staple Inn Actuarial Society in August 2004 by Simon Carne. In my opinion, still the best paper that has been presented to the society.

Chapter 6 is a summary of what has been going on in other countries, and the conclusion appears to be that the best minds in all of these countries have failed to come up with a perfect solution. 
Chapter 8 starts with an excellent commentary on the expression increasingly used in the pensions industry: "self-sufficiency". The first part of paragraph 8.3 explains why this is a flawed concept. I see it being used in communication material in the pensions industry in a way that borders on dishonesty. We have to face up to there being two separate calculations for us to do and disclose. If the solvency calculation generates unpleasant results, we do nobody any favours by dreaming up other calculations that give more palatable results and giving them a misleading name.

So then we come to Chapters 9-12, which contain the main proposals. The main proposal is to use a stochastic method to generate a range of possible expected future asset returns and use the covenant assessment to decide the appropriate level of confidence, resulting in the determination of the correct discount rate.

I give general support to this approach, not least because it has been in fairly widespread use for the last 10 years at one of the "big 3" consulting firms (where I used to work). I am also aware of its occasional use at three medium-sized consulting firms. The practical problems that I remember included the following:

- The feeling amongst clients that the answer emerged from a "black box".

- The difficulty in obtaining a covenant assessment so clear and reliable that it could be a simple input item for the process.

- The difficulty in using a covenant assessment with a time horizon of maybe a couple of years, if you are lucky, for modelling calculations covering several decades.

- The difficulty in working out what covenant ratings should map to what probabilities. Is $60 \%$ right for "strong" and 70\% right for "tending to strong"? In addition, a high probability of, say, $90 \%$ would typically take you to the far side of the solvency calculation.

- Points that I am hoping members will express opinions on in this evening's discussion are as follows:

- Is the regulator's frustration at covenant strength making only a small difference to investment and funding strategy an issue of design or an issue of implementation?

- Should we be more careful with the expression "self-sufficiency"?

- Does it make sense to allow for best-estimate investment returns in recovery plans? It makes funding calculations mathematically incoherent and I am fairly sure that it was not intended by the Department of Work and Pensions (DWP).

- What do those members already using a stochastic method for setting discount rates find are the strengths and weaknesses in practice?

The Chair: I will now open the discussion to the floor.

Mr B. L. Davies, F.I.A.: I am not a critic of the funding methods: I have been a scheme actuary. What I am not clear about from the paper is what is the problem.

If you do not have a clear idea of the problem it is very difficult to come up with a solution. Are people aware of many schemes, which are currently, or prospectively, going to be unable to pay their members' benefits because the actuary chose a discount rate of $3.5 \%$ instead of $2.5 \%$ ? Is that the problem? 
The only executive outcome of a valuation is what the employer is going to pay over the next 3 years, with the opportunity within those 3 years, of doing interim checks to see if it needs to change. There is a very long detailed "incomprehensible" valuation report, which for the trustees and sponsor employer sets out the employer's contribution over the next 3 years.

I welcome this work but we need to be a bit more modest in terms of what we are trying to achieve.

Mr C. Patel, F.I.A.: I speak as a pensions actuary. Back in 2010, discount rates were an emotive subject and Chris Daykin and I were commissioned by the IFoA to provide initial thought leadership on a discount rate project. Discount rates continue to be an emotive subject, because people link discount rates to the sustainability of pension schemes, which I fail to understand.

In the discount rate project, we came up with two observations. One was the distinction we made between the matching and the budgeting calculations, because that allowed pensions actuaries and their clients to think a lot more about the context and purpose of the calculations.

We also made a further recommendation which was that the communication of the discount rates as a single discount rate is one-dimensional and lacking, because each discount rate carries with it an embedded risk. We suggested that somehow that embedded risk also needed to be communicated.

In the work I have since done at the regulator, I have learnt that communicating the risk itself is not sufficient. We need to understand a lot more about how that risk is managed, and whether that management plan is effective.

With that background, I welcome this paper. The authors provide a good and sensible framework within which an actuary can think about these issues. More importantly, the actuary can engage the clients to think about: setting clear and long-term objectives; having some strategy to achieve them; understanding the risks embedded in that strategy; checking to see whether the funding plan is robust enough to withstand those risks; and also trying to understand what they would do if they found themselves on the wrong side of the risk.

Would the client, for example, need to resort to some extreme measures, which may be unfortunate and which may cause them to go back and rethink the strategy?

Above all, it is important to demonstrate that the trustees have thought through all of this. This is something about which the regulator has been emphasising recently.

I do not see enough valuation reports on a regular basis. We receive them only on request, and that does not happen all that often. When I do see them, I see very little which explains the thought processes behind the recommendations. That is, how it is that the actuaries come to the comfortable position that those risks are manageable without the sponsor having to resort to extreme measures.

This paper is a very good contribution to the debate that the regulator started over 4 years ago, and I welcome it. 
I would like to flag up two issues. It would have been good to see a link between scheme maturity and recovery plan lengths because this is important as schemes mature and they experience new risks which are important to manage.

I would have also liked to have seen some way of managing the big problem of lack of visibility in the long-term assessment of the covenant.

If you do not understand the long-term covenant, then that in itself brings in some risks which need to be factored into the funding plan.

Mr D. O. Cule, F.I.A.: Security is the key issue. That is what the members are hoping for. But $100 \%$ security is not necessary. In fact, not getting $100 \%$ is not a disaster, although getting nought percent as the Allied Steel and Wire (ASW) pensioners were exposed to could be a disaster. So funding for $<100 \%$ of buyout gives voice to the trustees saying how much they are willing to risk the members' benefits for the covenant of the employer. This is an interesting way of looking at things, by saying "I do not want to fund for $100 \%$ but I will let you, the member, run a risk, the risk being that you will not receive your benefits".

The history was interesting. Like Stephen (Rees), I thought it could go back further to where we could find the seeds of our own demise. There was a paper, "A pension scheme windup: legitimate act or smash-and-grab?” by S. M. Southall and J. D. Punter (1987). That showed that in the 1980s pension schemes were fully funded on buyout and schemes were being wound up and services taken away.

Times change. What caused the change? Inflation is the answer.

Inflation reduced benefits, and that was accepted and was acceptable. This what the PPF does. Reduction in benefit is acceptable to the PPF. Charles (Cowling)'s graphics showed that there are only two outcomes: you either receive a little bit more than PPF or you receive all your benefits. There is not that big gap in between.

We should as actuaries and in our scheme roles be looking to maximise that gap above the PPF. That would be putting members first. Unfortunately, it is not what TPR or PPF would like us to do. That challenge therefore goes to the PPF and TPR to be much more explicit about what minimum funding they require.

Meanwhile, if the IFoA want the profession to become involved in covenant measure, we need to revisit the 2005 paper on what actuaries can do on covenants, because that effectively stops actuaries doing covenant work. I have seen some draft legal advice which implies that when a scheme actuary has a contribution role to fulfil, they must obtain independent advice based on the IFoA's 2005 paper.

This interpretation limits the scope of the scheme actuary and may prevent actuaries becoming central to integrated risk management. Actuaries should be encouraged to become covenant specialists, just as they are encouraged to become investment specialists, so that we can advise on all three aspects of integrated risk management. It is not something that we should shy away from but something which we should encourage. 
It was useful to raise the financial economics arguments because they do help us see some issues. One issue is that there are three aspects to a pension scheme. There are the physical assets that you own the investments; there is a call on the employer; and there is a call on the PPF. That is what provides the members' benefit. To maximise two calls, you want volatility and volatility means risky investments. That is what financial economics tells us. Thus risky assets might be optimal for trustees if you follow financial economics.

There are a couple of areas we could look at. You could try to estimate loss like the insurers would do. Instead of expressing a valuation in terms of being X per cent funded, you might say that there is an expected loss of, say, $3 \%$ of benefits to members and the trustees' objective is to improve that. Alternatively, you could look at the risk of ruin, the chances of the scheme failing, which again is an insurance technique.

Mr D. P. Benstead, F.I.A.: I add to Bryn (Davies)'s questions where he asked: "what is the problem? How can we find an answer if we do not know what the problem is?"

I pose a different question: "What does a successful pension scheme look like?" If we do not know what a successful pension scheme looks like, how can we create an appropriate funding and investment plan?

I suggest a successful pension scheme is one which is open to new entrants and has a funding and investment strategy and an employer's share of the cost with which the employer is happy. An open scheme provides benefits for future generations of members as it has for past generations, minimising the inter-generational deficiencies of pension provision that are exercising many minds at the moment.

If we first decide on a design for benefits funding and investment which an employer would willingly sponsor for future service, then that gives us our guide for the funding plan of the scheme.

We should demonstrate that we are experts in provision of pensions by providing pensions. We do not demonstrate that expertise by shutting pension schemes down to new entrants and to future accrual. We demonstrate our expertise by showing where a successful compromise of benefits, contribution and risk lies, modifying schemes towards successful compromises involving schemes being open to new members.

Mr J. G. Spain, F.I.A.: I am speaking personally. We must thank Charles (Cowling) and his colleagues for this paper even if not all of us agree with all of it or perhaps any of it.

I am proud to be one of those cited in paragraph 1.1.2 in thinking that actuaries and trustees are being far too prudent, leading directly to pension scheme liabilities being overstated. This is especially true when one hears the very frequent, alarmist, aggregate projections, for example, that the schemes are $£ 200$ trillion in deficit. These are presented as if they are definitely going to happen and are somewhat high.

In paragraph 2.7.2, I find it very surprising that trustees' duties are defined by the reference to the regulator's webpage: these should be defined according to legal expertise. The regulator has a duty, but it is not to provide the legal advice to us or to anybody else. 
My main problems come from section 4, as I do not believe that financial economics are relevant. As financial scientists, which is what actuaries should be, we should be following the evidence. There is absolutely no evidence anywhere that financial economics has any relevance to the funding of longterm entities. I can accept its relevance in the short term but not in the long term. Market values do not have any predictive return power. Higher achieved investment returns must reduce costs for the same benefits. There is a huge concentration of risk as if it necessarily crystallises without any probability being ascribed to the risk of default.

Sixty-five years ago Frank Redington pointed out that if you pursue the lack of a loss, you also pursue the lack of a profit, which is not a good idea. Prudence is a great idea at somebody's expense. It would normally be the sponsor's expense. You can only define whether or not you are prudent if you know your best estimate. The presentation that we have just seen showed evidence based upon nominal discount rates. I am surprised that nominal discount rates are considered in any way useful for deciding whether, or not, there is any difference between CG1 and CG4 because it is real discount rates that matter. Each of those could have had their future inflation defined in different ways. If everybody has defined retail price inflation as the difference between the yields on long-term conventional gilts and long-term index-linked gilts, the evidence is that this way it overstates the true outcome. So that is probably not good.

The real problem is that the quantification cannot be adequately captured by scalars. One number does not describe all of the different things that can happen.

This brings us back to the discount rate as a problem, not as a solution. The discount rate was always the inverse operator of future investment returns. When we started we did not have the ability to do the sums going forward. We do now. We should be using that and then we can provide clients with proper advice such as if you keep contributions going at the current rate, you have a $30 \%$ chance of going bust within 10 years, or whatever it might be.

Stochastic processes give a better indication but they do not need to be black boxes. The actuary should be discussing suitable distributions with the trustees.

They could be cross-examined on their views and second opinions could be taken. Using a flat discount rate, or even two discount rates, does not give much information. It hides the information that fuels it. Why do we do that?

The one thing that I do agree with the authors about is that DB funding needs a great deal of attention. We need to do better than we are doing at the moment.

So council and the Pensions Board should commission another paper, which goes back to basics and looks further at the evidence. We should be doing something different, which should be more rounded in reality.

Mr C. Keating: My submission concerns a fundamental problem which is the idea that the purpose of funding is to pay benefits as they fall due, meaning after the sponsor has become insolvent. There is a significant problem with that which is that it breaches the principle of equity, a canon of English law. 
The irony is that it was another breach of the principle of equity, well-illustrated in ASW that led to the regulation that we have recently seen. The issue was the fact that pensioners in payment would continue to receive everything, while some active members could receive nothing. This created a great deal of concern.

A pension is simply a claim on future production. Funding is a method of acquiring assets today with the hope that they will produce sufficient returns in the future to pay benefits. If you consider the assets that you can purchase today and look at what proportion of the future production those assets are likely to generate, you will see that the problem is very difficult, or even impossible, to resolve.

You are in the land of imponderables as you cannot accurately forecast. No one can forecast sponsor insolvency likelihoods at horizons of 60 years or 70 years. Nor can you meaningfully forecast returns over that period of time.

Mr C. D. O'Brien, F.I.A.: This paper is relevant to the DWP paper issued earlier this year on the issues around the security and sustainability of DB schemes.

There is a problem with pension valuations, which should be addressed.

What I particularly like about the paper is the distinction it draws between budgeting calculations on the one hand and matching calculations on the other. Any discussion of pension funding has to recognise the difference between these two approaches.

The authors consider the scheme-specific-funding regime in the United Kingdom and are surprised that there is not a closer relationship between the choice of discount rates in calculating a scheme's TPs and the strength of the employer covenant. In their proposals, illustrated in appendix 2, the discount rate specifically reflects the employer covenant.

However, I would question whether this is appropriate. If an employer becomes financially stronger but assuming that the investment strategy of the pension scheme is unchanged, then I see no reason for the liabilities to be calculated differently.

There is a more straightforward approach. That is to say that the liabilities are unchanged but that the trustees may wish to take into account the greater strength of the employer in determining what is an acceptable investment strategy and what is an acceptable deficit. That is surely more transparent than adjusting the discount rate. It is consistent with integrated risk management.

In respect of the decisions on funding contributions and investment strategy, I would have preferred the paper to devote more attention to the different perspectives and attitudes to risk of sponsor and trustees. The trustees have to take into account the way that there is not uniformity among scheme members, for example, between pensioners and contributing members.

I now turn to what information should be presented to scheme members about the financial strength of the scheme. The authors conclude that member communication based on the budgeting calculation gives misleading information about the security of members' benefits. I agree and it is consistent with the conclusion of the Profession's discount rate project. Charles (Cowling) was one of the authors of the paper on the project. It is worth saying that the project began when the profession commissioned research on discount rates which was carried out by Chris Daykin and 
Chinu Patel. It was then taken forward by the management committee, appointing a steering committee of senior members across the range of the profession's interests, including pensions. They presented a sessional paper in 2011. This confirmed the appropriateness of the distinction between budgeting and matching calculations that Chris (Daykin) and China (Patel) had put forward.

In particular, the working party recommends that the funding information provided to pension scheme trustees, members and regulators should focus on the solvency position which produces a matching calculation. Budgeting calculations would not be reliable or adequate for that purpose.

However, what we find in practice is rather different. Members receive a summary funding statement showing a funding ratio where the assets are at market value and the liabilities of the TPs calculated with a discount rate which may be based on gilts yields or prudent expected investment returns.

Scheme members are not told what kind of discount rate has been used. This disclosure is largely meaningless, bearing in mind that the discretion in the choice of discount rate can lead up to $30 \%$ or $40 \%$ change in the liabilities.

Further, since the usual practice is for the discount rate in the TPs to reflect prudent expected investment returns, this is a budgeting calculation and not the matching calculation that is appropriate for member disclosure.

It is true that the summary of funding statement also usually discloses the funding ratio with the liabilities calculated as the insurance buyout cost. This is a form of matching calculation. Although, if the trustees do not intend to buy an insurance policy, it can be argued that the buyout costs inflate somewhat the costs to the trustees of meeting the liabilities themselves.

However, it is common in summary funding statements for the trustees to state that this information on the buyout cost is provided because it is required by regulation and the trustee has no intention of closing the scheme or buying insurance. The implication is that members should focus not on the funding ratio using the buyout cost, but instead on the funding position using the TPs.

The problem is that this is entirely inappropriate. The liabilities of the pension scheme depend on factors such as salary, length of service and longevity. They do not depend on investment strategy in the way that using TPs implies. There should be a matching calculation instead.

It is over 6 years since the sessional paper on the discount rate project and we have not seen the progress that I would have liked towards matching calculations being the focus of member disclosure. This may reflect the way that we have regulations on valuations and disclosure.

What was positive was that earlier this year the DWP issued a green paper and asked for comments on what information would be helpful to members to understand the funding position of their schemes. This is a golden opportunity for the profession to say that the focus should be on the matching calculations. One option would be to recommend that there is an emphasis on the insurance buyout costs rather than downplaying this cost. Alternatively, it would be possible to develop a matching calculation to liabilities where the discount rate is based on gilt yields or swaps and potentially an adjustment to reflect the illiquidity of pension liabilities. 
Unfortunately, the response to the DWP from the Pensions Board appeared satisfied with current practice. It is not clear whether the Pensions Board members reject the recommendations of the discount rate project that matching calculations should be a focus of disclosure to members. If so, it would be as well for the Pensions Board to be upfront about this, but also to recognise that they are at odds with the views of many members of the profession.

My hope is that the paper presented today will stir the Pensions Board into accepting that matching and not budgeting calculations are appropriate for informing members about the financial strength of their scheme. At present, there is the potential for members to be misled. The actuarial profession cannot stand by and do nothing. Pension valuations do need to change.

The Chair: Thank you all very much for the comments on the paper.

Charles (Cowling) will now respond.

Mr Cowling (responding): Thank you all for your comments. The IFoA will be happy to take any written comments. We as authors would also be very keen and happy to receive written comments.

We accept that there are many parts of this paper that could be explored further. I am not going to respond to every comment but pick up on a few of the questions that were raised.

I agreed with much of what was said by Stephen (Rees). We should not be fudging the two questions that I posed at the outset. They are separate questions and need separate answers. Similarly, I have reservations about self-sufficiency, where it is defined as something other than solvency, unless clear to all parties concerned the residual risk that still exists within that framework.

Both Bryn (Davies) and Derek (Benstead) asked: "what is the problem?"

The problem is clear. When the PPF was established, we had 7,800 pension schemes. We now have 5,800 pension schemes. The PLSA research estimates, and the PPF agrees with this, that at least 1,000 pension schemes will fall into the PPF over the next 20 or 30 years. In these schemes people will lose benefits.

It may be that people are happy with the PPF level of benefits, and that loss is an acceptable one in return for the benefit of sponsors not funding to a much more stringent level. I do not see that that is properly communicated to members. I agree with what Chris (O'Brien) said about some of our failings to communicate to members the fact that their benefits are at risk. In effect, that pensions schemes are different from insurance companies and that pensions benefits are risky benefits, whereas insurance company benefits, in theory at least, are guaranteed.

It is my view that where that risk is material, members should be told. Bryn (Davies) says the only output from a valuation is what the employer is going to pay. If that is the only output from the valuation, that is a pretty poor state of affairs. I would say that the output from the valuation should include helping the trustees and the members to understand the risk that benefits might not be paid.

Chinu (Patel) made many helpful comments and point to the helpful, supporting information that is on the regulator's website, particularly around covenants. There are clearly significant challenges 
about looking forward and trying to put a value on employer covenants well into the future. It is well-nigh impossible.

As a trustee of a pension scheme that means that the longer the timeframe I am looking at, the less risk I want to take. I want that to be clearly understood, and I want members to understand it. If I am taking a long-term bet that the employer is going to be there in 30 or 40 years, that needs to be clearly understood and the risk that that then potentially falls on members.

I fully accept that there are real challenges related to this. That does not mean we turn our back on them. Many people pointed to the importance of security, which is key in what we are trying to set out.

I agree it is about financing a long-term cash flow obligation. I accept Jon (Spain)'s point that if you condense everything into a single discount rate you are losing a lot of information.

That does not detract from the reality that the purpose of holding assets is to provide security. We need to measure that security and that is where matching calculations and the solvency calculation is all important.

This is a really important debate. Whether or not there is a paper to discuss, we, as pensions actuaries, need to revisit this debate on a regular basis.

The Chair: Cliff Speed has kindly agreed to provide some closing comments. He is responsible for the $£ 10$ billion investment portfolio of Pensions Trust Retirement Solutions. He is an experienced Chief Investment Officer and actuary with over 20 years' experience in risk management. He has worked in asset management, insurance, consultancy, investment banking and has been a university lecturer. On top of all that, he has published numerous papers on risk management for pension schemes.

Mr C. A. Speed, F.F.A. (closing the discussion): I should like to thank the authors and the contributors for reinvigorating the debate. My comments are my own and not any of my employers, past or present.

The paper provided an interesting history of MFR, provided a good analysis of TPR data and gave an interesting comparison of practices around the world. The crux of the paper is providing a framework that links funding from the employer to the sponsor covenant.

The authors recognise that a pension scheme is trying to provide funding for a long-term obligation, while providing security for members' benefits. These twin themes keep coming back throughout the debate.

Another element which has come out throughout the debate is the distinction between budgeting, which projects forward values to allow for expected returns, and the matching calculation, which is mostly used for transactional work.

Many important observations were made in the paper. It is worth reminding ourselves about the deficit on a buyout basis which is an unsecured loan, and that the actual asset allocation does not necessarily impact the value of the liabilities. 
From this strong foundation, the authors then proceed to develop a modelling framework where returns are projected at different discount rates depending on the covenant strength, and hence different TP measures, are provided.

So covenant, investment and funding had been synthesised into an integrated approach, as advocated by the regulator. Thus, the authors have succeeded in their aims.

There are also some good, strong recommendations: a better minimum funding standard is one linked to a matching calculation which has been previously suggested in this hall; a more transparent and fair approach would be to have an agreed percentage of buyout basis and target; an objective should be clearly stated and self-investment should be understood.

These are well researched and well thought-out conclusions.

The authors have helped to show what they would mean in practice if they were implemented. In appendix 2 there is an example. This example shows us solvency liabilities of $£ 202$ million, and assets of $£ 100$ million. The authors then point out that the deficit or the self-investment is the difference between those two values.

Next the proposed framework is applied. This needs a whole range of assumptions, as has been discussed, on asset allocation, returns, covenant strength and time horizon, et cetera.

From this we generate a TP of $£ 127$ million. This is some $£ 75$ million less than the solvency number. So I asked myself: how does this fit with the facts we had earlier? For example, that the asset allocation, because this is clearly based upon a $15 \%$ equity asset allocation, does not change the value of the liabilities. Now the deficit has gone from being about $£ 102$ million to $£ 27$ million. Does this fit in with the transparent communication which is the recommendation in the paper?

Some of you may say I am being unfair. It is clearly stated that the approach is budgeting. Have I fallen into that sin of mixing up matching and budgeting approaches?

Let us correct for that. Let me update the liabilities. It is quite subtle. You have to watch closely. The liabilities do not change. If I am doing a projection, I have projected them. It does not matter if I have $50 \%$ in equities or $100 \%$ in equities. The liabilities stay the same.

What appears to be happening is the wrong side of the balance sheet is being adjusted.

Here is an alternative presentation to the authors, which may be a fairer representation. What they are really saying is that you have a certain amount of assets. Over time, there will be some expected returns. These expected returns are, of course, uncertain. So we should allow for risk because the paper reminds us that it is a blunder for a fiduciary trustee to believe equity risk decreases over time. We need to think about and allow for risk.

In addition to that, there are deficit contributions. If these are added in, we find that we have a target of $63 \%$ of the solvency liabilities. It is that side of the balance sheet which is being amended. We still have the loan to the sponsor for self-investment. 
By way of example, if you are in the position of being funded to that solvency level, $£ 202$ million, and someone approaches the trustee and says: I have an excellent investment for you. You can make an unsecured loan, which has no repayment date, pays no interest and it is in a single entity: that is economically what the self-investment is on the right-hand side.

Is this a framework which we as a profession should be advocating? Different views have been expressed.

Considering the other parameters: if I apply the framework assuming $75 \%$ in equities, the TP value reduces to $£ 99$ million, which is $49 \%$ of the solvency value and a deficit becomes a surplus.

There may not be a perfect model but it is beholden to us to consider how this affects stakeholders. What motivations would this engender or would this facilitate good risk management? This approach requires more development.

There is much to commend this paper and it is time that this debate was reinvigorated. If experience is the name we give to our mistakes, as Wilde had it, then we have a lot of experience and we should be able to build upon that.

My personal opinion is that the authors have worked hard and done a good job trying to square the circle of how you get all these bits to fit within the regulatory framework.

What has gone wrong? It is not the authors' line of thought but trying to put it within the regulatory framework. I believe that the regulatory framework is flawed and does not encourage good practice.

I should like the authors, and maybe the profession, to be bolder and set out a coherent framework which will mean it will be better in the future.

The Chair: From the comments generated it is clear that this is an area that deserves additional debate. There is not a consensus among pension scheme actuaries as to how we incorporate covenant, investments and funding risk into a neat model but perhaps to do so would be irresponsible. This is a nuanced area and needs careful consideration about how we manage the interaction of key risks for each of our clients, whether they be the corporate sponsors or the trustees of the pension schemes that we advise.

It remains for me to express my thanks, and the thanks of everybody in the room, to the authors, opener and closer and all of those who participated in this evening's discussion. Thank you very much.

Post-meeting note:

Mr Derek Benstead sent in the following written contribution, which expands on the contribution he made at the meeting.

Written submission by Derek Benstead FIA, First Actuarial LLP

derek.benstead@firstactuarial.co.uk 0161868172107501588990 
What does a successful pension scheme look like? A successful pension scheme is one which is open to new entrants. An open scheme has a funding and investment strategy and an employer's share of the cost which the employer is happy with. An open scheme provides benefits for future generations as it has for past generations, thus minimising inter-generational differences of provision. Therefore, first decide on the design for benefits, funding and investment which an employer would willingly sponsor for future service, and let that be the guide for the funding plan of the scheme.

Let us demonstrate that we are experts in provision of pensions by providing pensions. We do not demonstrate our expertise by shutting pension schemes to new entrants and to future accrual. We demonstrate it by showing where the successful compromise of benefits, contribution and risk lies. We should be modifying schemes towards successful compromises, not closing them down.

In today's environment of bond yields, most trust schemes are not fully solvent on a buyout basis, the near equivalent of self-sufficiency in gilts. Such a scheme will provide a smaller benefit after employer insolvency than it did before.

If the scheme's benefits were set at a level which could be insured in full, and the scheme is invested in matching assets, then the outcome is benefits before employer insolvency which are as small as they are after insolvency. It is of no advantage to members if, to solve the problem of benefits being smaller after employer insolvency, we make the benefits equally small before insolvency. The likely response of an employer to an invitation to sponsor accrual on buyout funding and matching assets basis is to be to decline to sponsor accrual at all, on grounds of the extreme cost inefficiency, and this would be a failure of design.

If the defined scheme's benefits are set at a level which can be insured in full, and the scheme is invested in more rewarding assets, then to the extent that the assets perform well, discretionary additional benefits may be awarded. Then before employer insolvency, there is a combination of defined and discretionary benefits. After insolvency, the discretionary benefits mostly disappear and the defined benefits are fully insured. This approach to benefit design may make it more transparent to members which part of their benefits may be delivered after employer insolvency and which part may be mostly lost. It also has the merit of making the scheme more manageable while the employer is solvent. Manipulation of the discretionary benefit can be used as a level of funding control, as well as or in replacement of manipulation of the employer's contribution rate.

That benefits are smaller after an employer's insolvency is the inevitable consequence of changing from more cost efficient to less cost efficient pension provision. The same quantity of assets is bound to provide smaller benefits if spent less cost efficiently. There is no merit in resolving this by making benefit provision before employer insolvency as cost inefficient as it is after employer insolvency, by funding and investing on a self-sufficiency in gilts basis.

The government recognised this when it reformed the statutory funding requirements. It noticed the high cost of solvency funding which results in either unaffordable costs before employer insolvency or benefit reductions after employer insolvency. It solved the problem by inventing the Pension Protection Fund. Constitutionally, the PPF is not an insurance company. Neither should it behave like an insurance company, because to do so would recreate the problem which PPF was set up to solve. The PPF is a pension scheme sponsored, ultimately, by employers, through the levy system. 
Now, whether the employer is solvent or not, its benefit promises can be provided by an employer sponsored pension scheme, minimising the change in cost efficiency otherwise triggered by employer insolvency.

If we are not satisfied with PPF compensation as a minimum post-insolvency benefit, then let's improve the PPF until we are. Lifting the cap on compensation to cover all pension accrued within the rules for tax approved pension provision, and introducing pension increases for pension from pre-1997 service if a scheme provided any increases on pre-1997 pension would be two good improvements to make.

Investment risk is not the leading risk criterion in a pension scheme and returns on gilts and gilt yields are not the yardsticks by which everything else must be judged. I propose that three good risk criteria for making judgements in a pension scheme are:

Does an action increase the probability of paying the benefits in full?

Does an action increase the probability of the employer's share of the cost falling within what it is able to pay?

And within what it is willing to pay?

These three criteria go together. Members' benefits are payable in full while the employer is solvent. If the package of benefits, funding and investment strategy has a cost falling within the employer's ability to pay, members get their benefits in full. If the cost falls within the employer's willingness to pay, the scheme stays open to accrual and inter-generational differences are minimised.

If an employer is financially weak and contributing at its limit of affordability, actions should be judged by whether they raise the likelihood of paying the benefits in full.

In cash-constrained circumstances, with $<100 \%$ funding on a gilt yield basis, it is not benefit risk reducing to invest more in gilts. Investing wholly in gilts may make it certain that the benefits cannot be paid, not certain that they can. Investing in a combination of growth assets and short-dated bonds to cover net outgo for a number of years may have a high probability of paying the benefits in full.

The Pensions Regulator, and this paper, uses the phrase "The employer underwrites the investment strategy". This is not a helpful formulation. The employer underwrites the benefits, not the investment strategy. Alongside the contributions, the purpose of the investment strategy is to provide for the benefits. The investment strategy which is most likely to pay the benefits is the one to choose in cash constrained circumstances.

The paper proposes the distribution of expected returns above gilts as a criterion for judging investment strategies. It is hard to see the relevance of making a judgement relative to gilts.

The judgement should be made relative to the criteria of whether the benefits are likely to be paid in full within a cost acceptable to the employer.

The Pension Regulator's formulation suggests funding can be to a lower level while an employer is strong, but if an employer becomes weak it should then fund to a higher standard, and the scheme 
should invest more in bonds. It is no surprise that TPR's formulation is not observed in practice. Weak employers cannot afford it. It would make more sense for better off employers to contribute more while they are stronger, in the reverse of TPR's formulation. It would make more sense still to recognise that the importance of the employer's covenant is not that it should affect the funding target or the investment strategy in the manner TPR would have it, but that it should affect the judgement of the contributions payable and the design of the benefits to be provided.

The paper repeats the misapplication of the Modigliani Miller theorem exposed by Simon Carne in his 2004 paper "Being actuarial with the truth". A pension scheme does not raise capital by issuing bonds and equities. It buys bonds and equities as the means of production of pensions. This paper is available on the internet and is an excellent read.

It is simply not true that defined benefit promises were issued without caveats of default risk. I have yet to see a member booklet which does not say that in the event of the employer insolvency the benefits might not be insured in full. In my experience, after an employer insolvency and a reduction of benefits to PPF levels, it is rare for a member to write in and complain about the benefit reduction.

I do not agree that a cash flow analysis complicates matters. In my experience, the transparency of cash flow planning is an aid to decision making, not a hindrance. If a model gives problematic output, we should first distinguish whether the model is telling us something about the real world which needs to be dealt with, or whether there is an unrealistic problem in the model, which can be disregarded. A cash flow analysis can help make this distinction.

While studying for my first actuarial exam, I learnt that the internal rate of return on an investment is the rate of return which valued the expected income as the cost of making the investment. I am surprised to see the section on modelling expected investment returns nowhere mentions explicitly the internal rate of return. The internal rate of return can be estimated for each of the major asset classes. The internal rate of return on the portfolio provides a discount rate for valuing asset income and benefit outgo which is consistent with the assets' market value. I highly recommend it.

The discussion of the paper touched on the disclosure of funding levels to members, the meaninglessness of reporting the technical provisions funding level without also explaining the TPs target, and the danger of reporting the buyout solvency level with wording alongside suggesting it is not important. I suggest that the first two things to explain to members are, (1) that their defined benefits are payable in full for as long as the sponsoring employer remains solvent, and, (2) if their sponsoring employer becomes insolvent the minimum benefit which will be paid is Pension Protection Fund compensation. This is most of what members need to know, the funding levels are of much less importance than these two statements.

To conclude, the major objective of a pension scheme is not the minimisation of funding and investment risk, but the provision of benefits and the minimisation of risk to the provision of benefits. If we close schemes to new entrants and to accrual, we have failed in the most basic objective of all, to provide pensions to the future generations who cannot join.

I recommend that we first decide on the design for benefits, funding and investment which an employer would willingly sponsor for future service, and let that be the guide for the funding plan of the scheme. 